\title{
Discrete subaortic stenosis
}

\author{
M M KHAN, M P S VARMA, J CLELAND, H O O'KANE, S W WEBB, \\ H C MULHOLLAND, A A J ADGEY \\ From the Regional Medical and Surgical Cardiology Centres, Royal Victoria Hospital, Grosvenor Road, \\ Belfast, $N$ Ireland
}

SUMMARY Data concerning 17 consecutive patients with discrete subaortic stenosis are recorded. Twelve patients underwent operative resection of the obstructing lesion. Of these all except one were symptomatic and all had electrocardiographic evidence of left ventricular hypertrophy or left ventricular hypertrophy with strain. They had a peak resting systolic left ventricular outflow tract gradient of $>50 \mathrm{mmHg}$ as predicted from the combined cuff measurement of systolic blood pressure and the echocardiographically estimated left ventricular systolic pressure and/or as determined by cardiac catheterisation. The outflow tract gradient as predicted from $\mathrm{M}$-mode echocardiography and peak systolic pressure showed close correlation with that measured at cardiac catheterisation or operation. During the postoperative follow-up from one month to 11 years, of 11 patients, one patient required a further operation for recurrence of the obstruction four years after the initial operation. All patients are now asymptomatic.

Five patients have not had an operation. The left ventricular outflow tract gradient as assessed at the time of cardiac catheterisation was $<50 \mathrm{mmHg}$. One patient has been lost to follow-up. The remaining four have been followed from four to eight years and have remained asymptomatic and the electrocardiograms have remained unchanged.

Careful follow-up of all patients is essential with continuing clinical assessment, electrocardiograms, M-mode and two-dimensional echocardiograms, and if necessary cardiac catheterisation. Prophylaxis against bacterial endocarditis is also essential.

Discrete subaortic stenosis has been recognised for many years and may account for 8 to 30 per cent of patients with congenital left ventricular outflow tract obstruction. ${ }^{1-3}$ Many patients are in the paediatric age range but it has also been recorded in adult patients. ${ }^{2-5}$ It has been reported that the left ventricular outflow tract obstruction in discrete subaortic stenosis may be progressive. ${ }^{16}$ While the echocardiographic features of this condition have been described, ${ }^{34-11}$ little information is available on the echocardiograms in patients during the follow-up or postoperative periods. ${ }^{7-10}$ In this study we describe the clinical, electrocardiographic, echocardiographic and haemodynamic features, operative findings, and follow-up of 17 patients with discrete subaortic stenosis.

\section{Patients and methods}

All 17 consecutive patients were diagnosed and followed at this centre between 1969 and 1980 . Cardiac catheterisation and angiography were carried Received for publication 12 March 1981 out in 16 patients under local anaesthesia. M-mode echocardiography was performed in 13 patients using a Smith-Kline Ekoline 20-A echocardiograph with a $2.25 \mathrm{MHz}$ transducer focused at $7.5 \mathrm{~cm}$, and coupled to a strip-chart recorder. In seven patients, twodimensional echocardiography was performed preoperatively with a Varian Phased Array V-3500. For those patients requiring operation, $M$-mode and two-dimensional echocardiographic studies were performed within 72 hours of the operation and for those who have not had an operation, within 72 hours of cardiac catheterisation.

The left ventricular outflow tract dimension was measured as the distance between the septum and the first recognised closure point of the mitral valve below the level of the aortic valve (see Fig. 4). This measurement extended from the anterior edge of the mitral valve echo to the posterior endocardial edge of the interventricular septal echo, and was made on sweeps from the aorta to the left ventricle. The peak systolic outflow tract gradient was predicted by subtracting the cuff measured brachial arterial peak 
systolic pressure from the estimated peak left ventricular systolic pressure. This was calculated from the echocardiogram by multiplying the peak systolic left ventricular circumferential wall stress by the ratio of left ventricular end-systolic wall thickness to left ventricular end-systolic cavity dimension. Peak systolic wall stress has been studied in patients with varying degrees of left ventricular hypertrophy secondary to chronic increase in afterload. When the left ventricle hypertrophies it has been shown that the peak systolic wall stress remains within a narrow range. Thus, in the absence of heart failure or left ventricular dilatation a constant $k$ has been derived and used as an index of left ventricular systolic wall stress $\left(k=225 \mathrm{mmHg}^{12}{ }^{13}\right)$. The end-systolic wall thickness was measured as the mean septal and posterior wall thickness at end-systole. The left ventricular posterior wall end-systolic thickness was measured from the inner surface of the endocardium to the outer surface of the epicardium at the point of maximal anterior motion of the posterior wall. Septal thickness was measured from the left ventricular to the right ventricular endocardium. The measurement of left ventricular cavity dimension was made from the endocardial inner surface of the interventricular septum and the posterior wall at end-systole.

Twelve patients have undergone cardiac surgery for resection of the subaortic stenosis. Operation was performed using conventional techniques of cardiopulmonary bypass with hypothermia in all patients. In addition cold cardioplegic solutions have been used for myocardial protection in seven patients. Median sternotomy was carried out and the aorta was opened either transversely or obliquely above the noncoronary cusp. The aortic valve was inspected and retracted to expose the subaortic area. The obstructing diaphragm or ridge was excised taking care to avoid injury to the anterior leaflet of the mitral valve, aortic valve cusps, and conducting tissue. If the diaphragm or ridge was attached to the aortic or mitral leaflets then it was detached from them. Myotomy was carried out in all the patients and the incision was made just below the right and left coronary cusp commissures in the outflow tract. Two patients had a wedge resection of the left ventricular outflow tract because of hypertrophy of the muscle in this region. One patient also required aortic valve replacement. Pre- and post-resection left ventricular outflow tract gradients were assessed in all patients. The follow-up of patients not requiring operation and those having operation has extended to 11 years.

\section{Results}

At the time of cardiac catheterisation or operation the ages of the patients ranged from 6 to 25 years (mean
14). There were nine female patients. Twelve patients had symptoms when assessed at the time of cardiac catheterisation and/or operation (Table 1). The commonest symptoms were tiredness and lethargy in eight patients, dizziness in seven, shortness of breath on exertion in six, chest pain in three, syncope in one, and palpitation in one. All patients had a loud systolic murmur accompanied by a thrill at the left sternal edge and base of the heart. The murmur was heard maximally in the second and third left intercostal spaces and radiated into the carotids. No patient had an ejection click though two had a bicuspid aortic valve. Fourteen patients had an immediate early diastolic murmur audible at the left sternal edge. One patient had wide splitting of the second sound, but none had paradoxical splitting.

The peak resting systolic left ventricular outflow tract gradient in patients with symptoms ranged from 30 to $170 \mathrm{mmHg}$ (mean $94 \mathrm{mmHg}$, Table 1). This gradient was assessed either at cardiac catheterisation or intraoperatively where no preoperative cardiac catheterisation was carried out. (Case 15 had two operations and the gradient taken was that preceding the first operation). In patients without symptoms the gradient ranged from $26-70 \mathrm{mmHg}$ (mean 43 $\mathrm{mmHg}$ ). When the mean gradient in patients with symptoms was compared with that in those without them the difference was statistically significant $(\mathrm{P}<0.05$, Student's t test $)$.

In 15 patients the electrocardiogram at the time of cardiac catheterisation and/or operation showed left ventricular hypertrophy. Eight had left ventricular hypertrophy with strain as shown by inverted $T$ waves in the lateral praecordial leads. Within six years of the initial presentation, nine patients developed left ventricular hypertrophy or a strain pattern occurred in association with left ventricular hypertrophy; in three of these nine patients (cases 4,5 , and 11) a strain pattern developed in association with left ventricular hypertrophy within three years of the initial electrocardiogram. At the initial presentation, cases 5, 8, and 11 had cardiac catheterisation. Two of these (cases 5 and 11) showed a definite increase in the outflow tract obstruction as predicted by echocardiography or by repeat cardiac catheterisation before operation. The electrocardiographic changes coincided with the increase in the outflow tract gradient.

The peak resting systolic left ventricular outflow tract gradient in patients with left ventricular hypertrophy ranged from 30 to $170 \mathrm{mmHg}$ (mean 86 $\mathrm{mmHg}$, Table 1). In eight patients who showed left ventricular hypertrophy with strain, the outflow tract gradient ranged from 50 to $170 \mathrm{mmHg}$ (mean 105 $\mathrm{mmHg}$ ). In the patients without left ventricular hypertrophy, the outflow tract gradients were 26 and $32 \mathrm{mmHg}$. All patients with symptoms had either left 
Table 1 Details of 17 patients with subaortic stenosis

\begin{tabular}{|c|c|c|c|c|c|c|c|c|}
\hline \multirow[t]{2}{*}{ No. } & \multirow[t]{2}{*}{$\begin{array}{c}\text { Age } \\
(y)\end{array}$} & \multirow[t]{2}{*}{ Sex } & \multirow{2}{*}{$\begin{array}{l}\text { Symptoms } \\
\text { at cardiac } \\
\text { catheterisation } \\
\text { and/or operation }\end{array}$} & \multirow{2}{*}{$\begin{array}{l}\text { Electrocardiogram } \\
\text { at cardiac } \\
\text { catheterisation } \\
\text { and/or operation }\end{array}$} & \multicolumn{3}{|c|}{$\begin{array}{l}\text { Gradient across left } \\
\text { ventricular outflow tract }(\mathrm{mmHg})\end{array}$} & \multirow[t]{2}{*}{ Operation } \\
\hline & & & & & $\begin{array}{l}\text { Predicted } \\
\text { by echo }\end{array}$ & $\begin{array}{l}\text { Cardiac } \\
\text { catheterisation }\end{array}$ & Intraoperative & \\
\hline 1 & 23 & $\mathrm{~F}$ & SOB, D, P & LVH + strain $\dagger$ & 127 & - & 105 & Yes \\
\hline 2 & 8 & $M$ & SOB, L, CP & LVH + strain & - & $\begin{array}{l}135 \\
(10-15)\end{array}$ & & Yes \\
\hline 3 & 9 & $M$ & $\mathrm{~L}, \mathrm{D}, \mathrm{SOB}$ & LVH + strain $\dagger$ & 78 & 65 & & Yes \\
\hline 4 & 12 & M & $\mathrm{D}, \mathrm{L}$ & LVH + strain $\dagger$ & 103 & 90 & & Yes \\
\hline \multirow[t]{2}{*}{5} & & & & & 60 & 48 & & \\
\hline & 16 & $M$ & D & LVH + strain $\dagger$ & (122) & & 130 & Yes \\
\hline 6 & 9 & $M$ & None & LVH† & 66 & 40 & & - \\
\hline 7 & 6 & $\mathbf{F}$ & None & LVH $†$ & 60 & 70 & & Yes \\
\hline \multirow[t]{2}{*}{8} & & & & & - & 40 & & \\
\hline & 25 & $\mathbf{F}$ & SOB, L & LVH + strain $\dagger$ & 66 & & $50 \Omega$ & Yes \\
\hline 9 & 14 & $\mathrm{~F}$ & None & LVH & 56 & $46 \Omega$ & & - \\
\hline 10 & 12 & $\mathrm{~F}$ & None & LAD & 40 & 32 & & - \\
\hline \multirow[t]{2}{*}{11} & & & & & - & 37 & & \\
\hline & 17 & $\mathbf{F}$ & CP, D & LVH + strain $\dagger$ & 111 & (95) & & Yes \\
\hline 12 & 11 & M & None & No LVH & 44 & 26 & & - \\
\hline 13 & 17 & $\mathbf{F}$ & $\mathrm{D}, \mathrm{L}$ & LVH & - & 68 & & Yes \\
\hline 14 & 16 & $M$ & $\mathrm{~L}, \mathrm{SOB}$ & LVH & - & 30 & & - \\
\hline 15 & $17 \ddagger$ & $\mathbf{F}$ & $\begin{array}{l}\mathrm{D}, \mathrm{CP}, \mathrm{L} \\
\text { SOB }\end{array}$ & LVH + strain & - & $\begin{array}{l}170) \\
(98)\}\end{array}$ & & Yes $\times 2$ \\
\hline 16 & 14 & M & $S$ & LVH & 70 & 75 & & Yes \\
\hline 17 & 9 & $\mathbf{F}$ & $\mathrm{L}$ & $\mathrm{LVH} \dagger$ & 92 & 118 & & Yes \\
\hline
\end{tabular}

*, Age at cardiac catheterisation or operation. $t$, Electrocardiogram showing progression to LVH (left ventricular hypertrophy) or left ventricular hypertrophy with strain from time of initial presentation. $\ddagger$, Age at first operation. $\S$, Gradient from left ventricle to aorta as bicuspid aortic valve present. Echo, M-mode echocardiogram; SOB, shortness of breath on exertion; D, dizziness; $P$, palpitation; L, lethargy; $\mathrm{CP}$, chest pain; S, syncope; LAD, left axis deviation; (), repeat echocardiogram or repeat cardiac catheterisation.

ventricular hypertrophy or left ventricular hypertrophy with strain on the electrocardiogram (Table 2).

Chest $x$-ray film showed an increase in the cardiothoracic ratio of $>55 \%$ in 8 patients. Only two patients showed dilatation of the ascending aorta. One of these had a bicuspid aortic valve.

\section{ECHOCARDIOGRAPHY}

$M$-mode echocardiography carried out in 13 patients showed early systolic closure of the aortic valve cusps in 12 (Table 3, Fig. 1). In the remaining patient (case 8) with a bicuspid aortic valve, one of the aortic cusps was flail after bacterial endocarditis. Seven patients showed early systolic closure of the right coronary cusp, that is the anteriorly placed cusp, four had early

Table 2 Symptoms, left ventricular hypertrophy as determined by Electrocardiogram and outflow tract gradient at cardiac catheterisation or operation in 17 patients with subaortic stenosis

\begin{tabular}{llll}
\hline Symptoms & No LVH & LVH & LVH + strain \\
\hline Asymptomatic & $2(29 \mathrm{mmHg})$ & $3(52 \mathrm{mmHg})$ & - \\
Symptomatic & - & $4(73 \mathrm{mmHg})$ & $8(105 \mathrm{mmHg})$ \\
\hline
\end{tabular}

(), Mean outflow tract gradient; LVH, Left ventricular hypertrophy. systolic closure of both the right and non-coronary cusps, and one showed only early systolic closure of the non-coronary cusp. Fine flutter of the aortic cusps was present in all except the patient with the flail aortic cusp. Fine flutter of the anterior mitral leaflet was present in all patients, and case 8 with severe aortic regurgitation showed premature mitral valve closure.

Two patients showed echoes in the left ventricular outflow tract. In one it was caused by prolapse of a flail aortic cusp occurring after bacterial endocarditis In the other multiple echoes were found in the left ventricular outflow tract but no distinct diaphragm could be detected (Table 3, Fig. 2). Two-dimensional echocardiography, however, identified the subaortic diaphragm or ridge in seven patients (Table 3, Fig. 3). Left ventricular outflow tract dimension was reduced in all patients (Table 3, Fig. 4).

There was a good correlation between the peak resting systolic left ventricular outflow tract gradient as predicted from the echocardiogram and peak systolic pressure and that measured haemodynamically (Tables 1,3 , Fig. $5(r=0.89)$ ).

Three patients showed systolic anterior motion of the anterior mitral valve leaflet, and one of them (case 4) also had asymmetric septal hypertrophy (the septal 


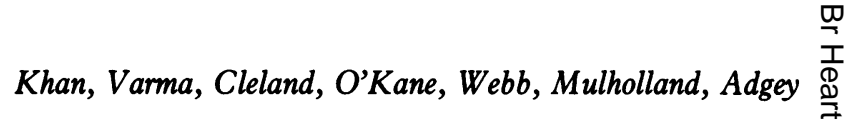

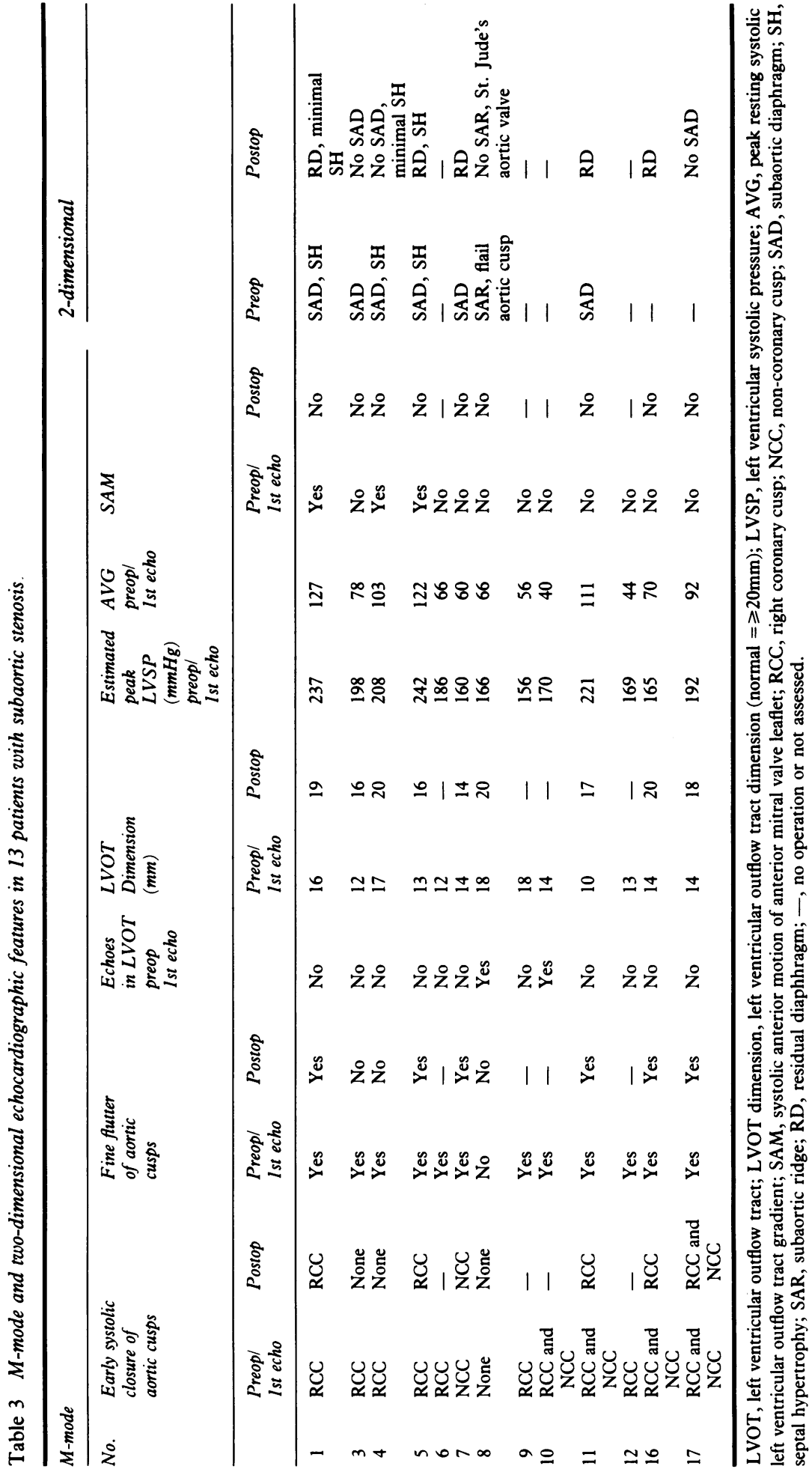

$\stackrel{\check{c}}{\Rightarrow}$

$\stackrel{\vec{P}}{\stackrel{9}{9}}$

$\frac{\overline{0}}{\frac{0}{\overline{0}}}$

๙

$\overrightarrow{0}$

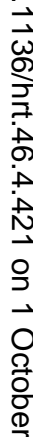

$\stackrel{\square}{\vec{\emptyset}}$

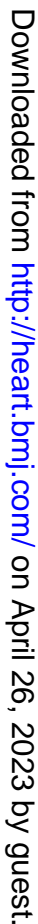

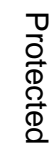




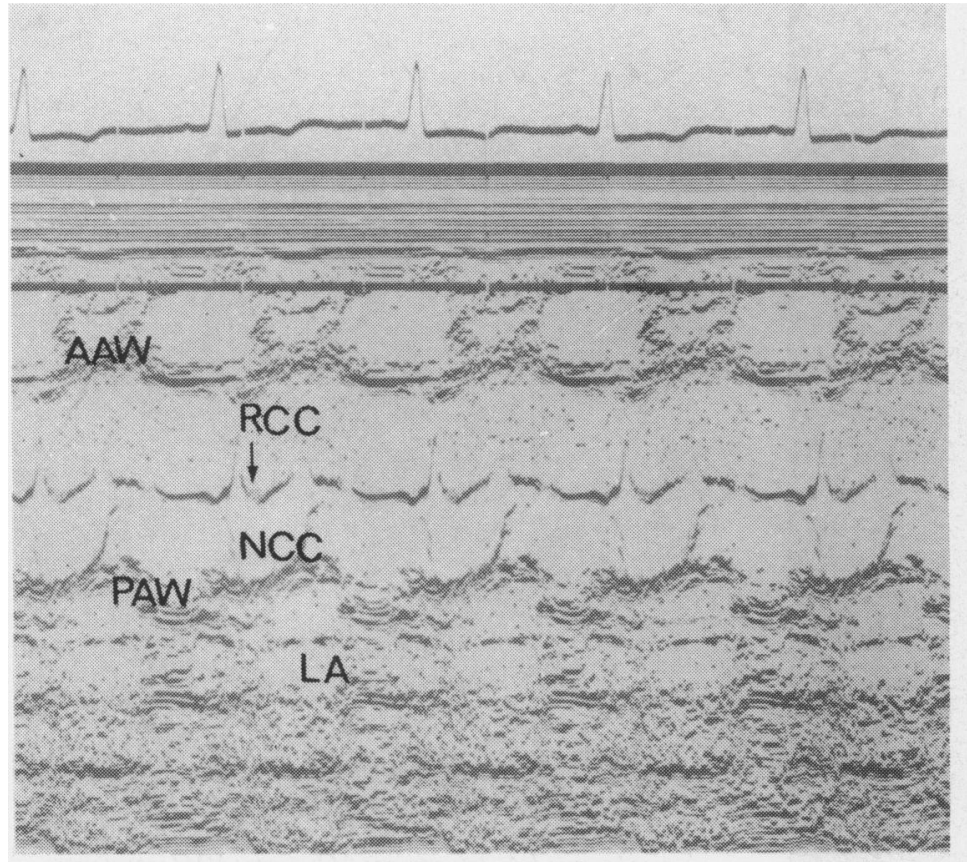

Fig. 1 Early systolic closure of the right coronary cusp of the aortic valve as indicated by the arrow in patient with subaortic stenosis. $A A W$, anterior aortic wall; $R C C$, right coronary cusp; $P A W$, posterior aortic wall; NCC, non-coronary cusp; $L A$, left atrium.

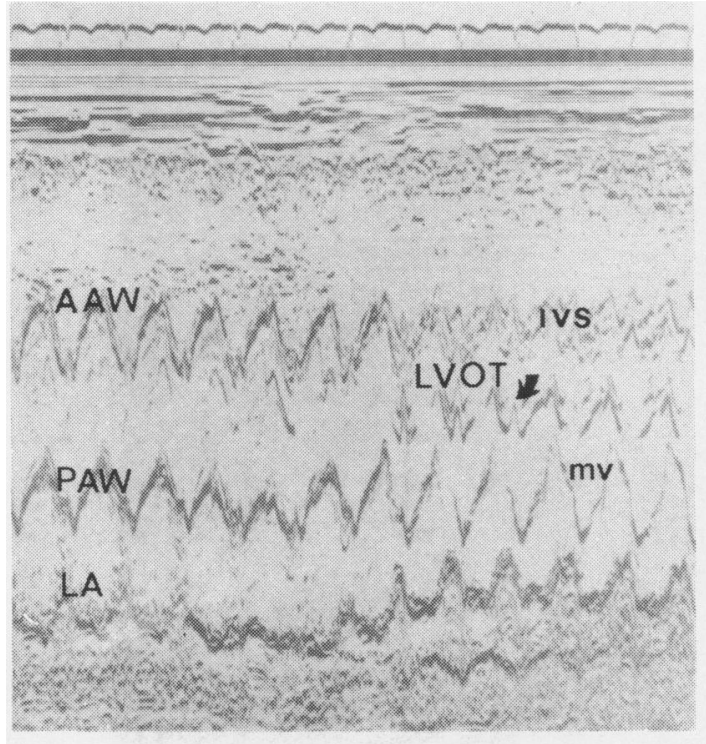

to left ventricular posterior wall ratio was $1.4: 1$ ) (Table 3). A subaortic diaphragm was identified in all three patients by two-dimensional echocardiography. Two of these patients had left ventricular angiography which confirmed a subaortic diaphragm. In neither patient did the left ventricular cavity show the characteristic appearance of hypertrophic obstructive cardiomyopathy.

Nine patients with preoperative echocardiograms had this repeated postoperatively (Table 3 ). In only three of the nine patients were early systolic closure of the aortic cusps and fine flutter of the aortic leaflets absent. In eight patients a minimal increase in the left ventricular outflow tract dimension had occurred. The systolic anterior motion of the anterior mitral valve leaflet in three patients and the asymmetric septal hypertrophy in one shown preoperatively by M-mode echocardiography were not present postoperatively. A residual diaphragm was demonstrated by two-dimensional echocardiography in five patients (Table 3).

\section{CARDIAC CATHETERISATION}

Sixteen patients had cardiac catheterisation with angiography (Table 1). All 16 had a pull-back peak resting systolic gradient demonstrated from the left ventricle to the left ventricular outflow tract. The

Fig. 2 Multiple echoes in the left ventricular outflow tract as shown by the arrow in patient with subaortic stenosis. $I V S$, interventricular septum; $M V$, mitral valve; $L V O T$, left ventricular outflow tract. mean peak resting systolic left ventricular outflow tract gradient at the time of the first cardiac catheterisation was $68 \mathrm{mmHg}$ (range 26 to 170 

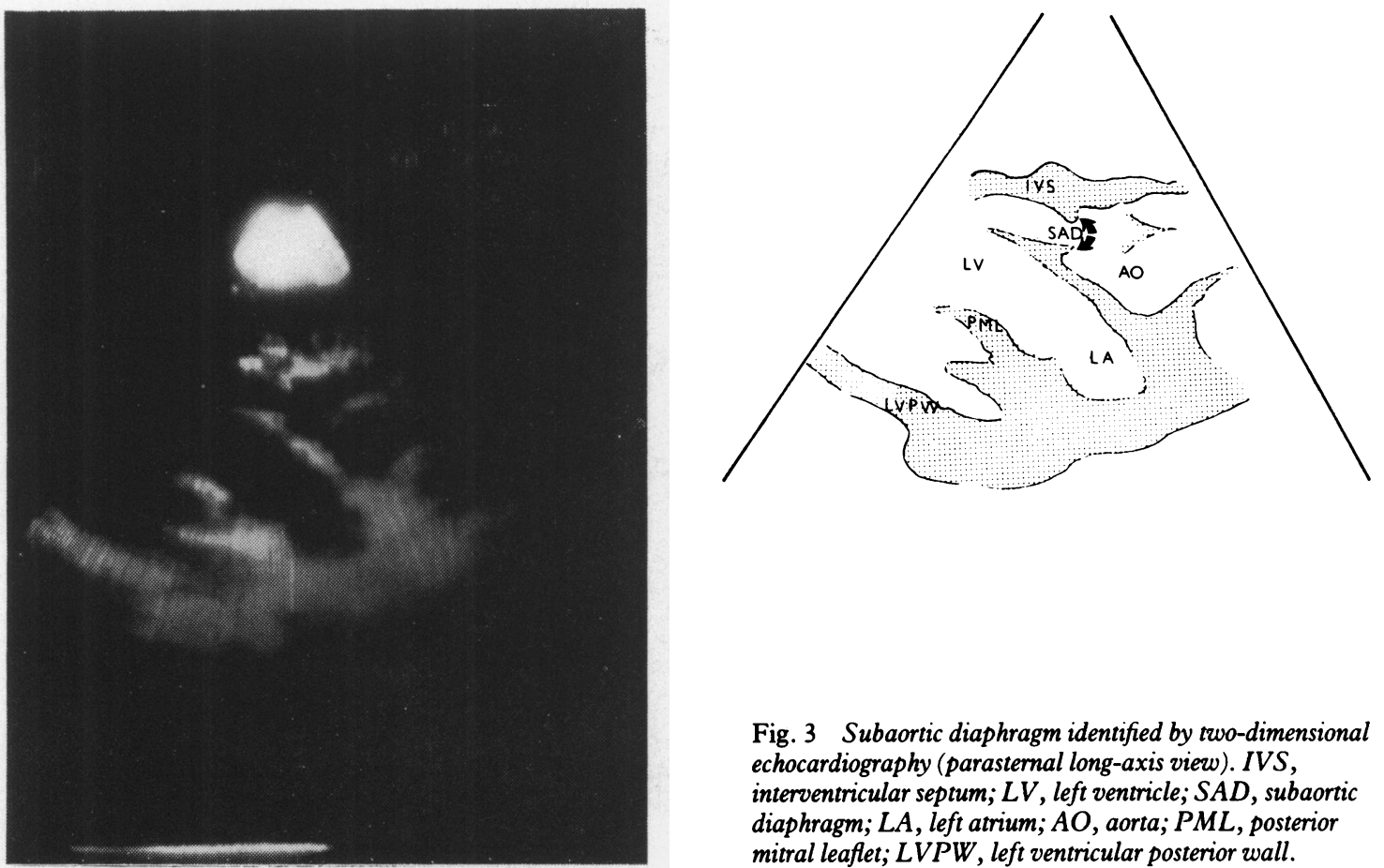

Fig. 3 Subaortic diaphragm identified by two-dimensional echocardiography (parasternal long-axis view). IVS, interventricular septum; $L V$, left ventricle; $S A D$, subaortic diaphragm; LA, left atrium; $A O$, aorta; $P M L$, posterior mitral leaflet; $L V P W$, left ventricular posterior wall.

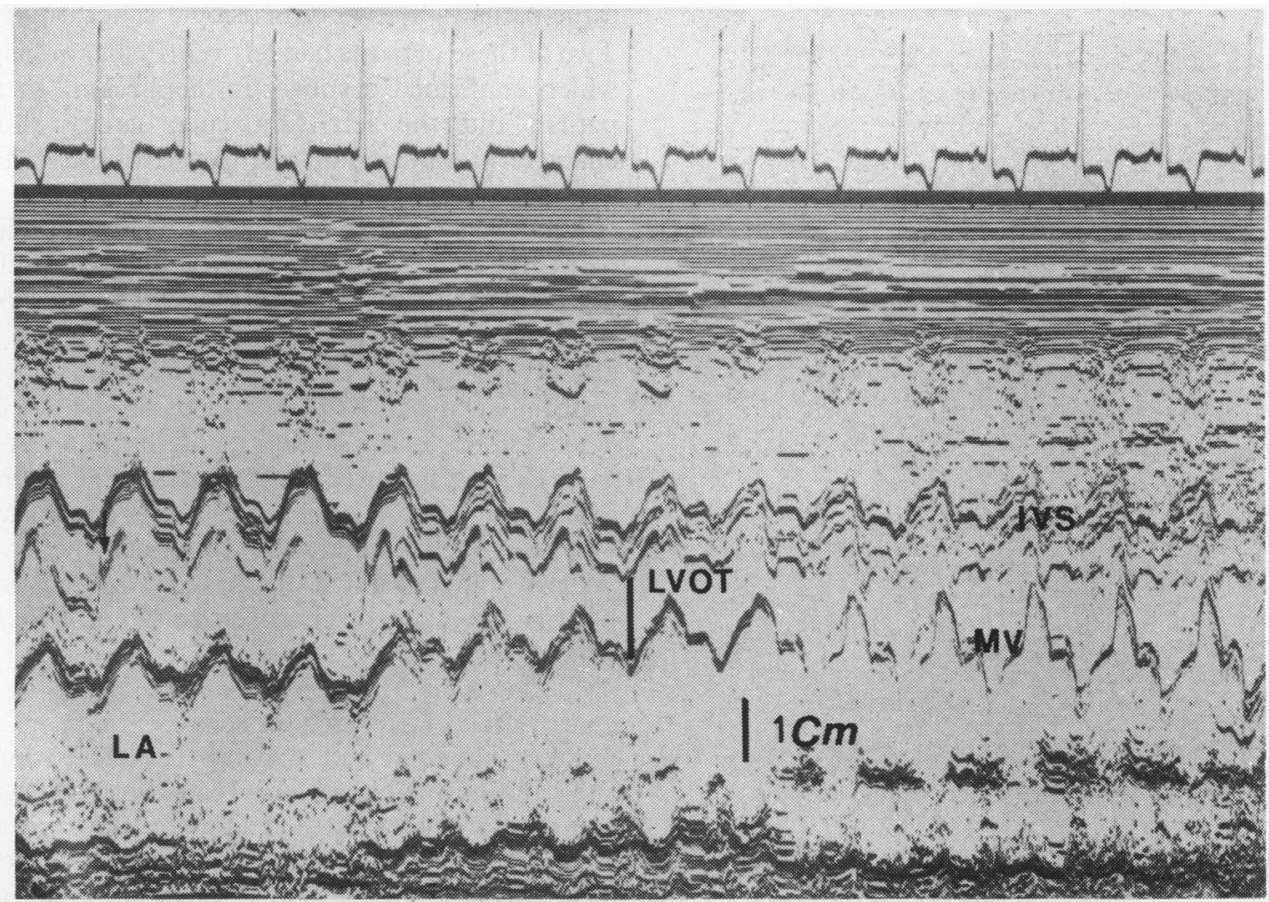

Fig. 4 Measurement of left ventricular outflow tract dimension. Arrow indicates early systolic closure of right coronary cusp of aortic valve. 


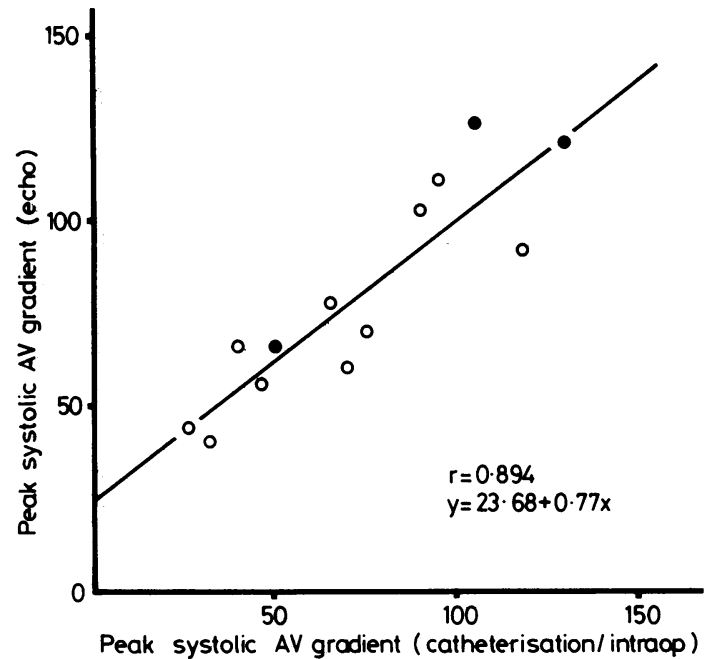

Fig. 5 Peak resting systolic left ventricular outflow tract gradient as predicted from echocardiogram and peak systolic pressure, related to that measured haemodynamically.

Black circles are measurements taken intraoperatively.

$\mathrm{mmHg}$ ). A discrete diaphragm was demonstrated in the subaortic region in all patients on angiography. Angiography demonstrated aortic regurgitation in 15 patients, though only 14 had an early diastolic murmur. Regurgitation was mild in 12 and moderate in three. One of these three (case 8) with initially moderate aortic regurgitation developed bacterial endocarditis on a bicuspid aortic valve which resulted in severe aortic regurgitation.

The coincidental lesions documented at the first cardiac catheterisation were a bicuspid aortic valve in two patients, a short segment coarctation of the aorta in one, and a patent foramen ovale in one. Three patients had a left-sided superior vena cava.

Cardiac catheterisation was repeated in three patients (Table 1). In case 11 , there were increasing symptoms over three years, accompanied by a change in the electrocardiogram to left ventricular hypertrophy with strain. From the $M$-mode echocardiogram and cuff systolic pressure it was predicted that the outflow tract gradient had increased to 111 $\mathrm{mmHg}$. At repeat cardiac catheterisation a pronounced increase in the outflow tract gradient had occurred from 37 to $95 \mathrm{mmHg}$. Two patients required cardiac catheterisation after operation. In one (case 15) there was persistence of left ventricular hypertrophy with strain pattern on the electrocardiogram and when symptoms recurred four years after the initial operation the gradient was found to be 98 $\mathrm{mmHg}$ necessitating repeat operation. In case 2, second degree atrioventricular block developed at the time of operation. On discharge, the patient had intermittent second degree atrioventricular block. Four years after operation he was readmitted with complete heart block and congestive heart failure. Repeat cardiac catheterisation showed a gradient in the outflow tract of only 10 to $15 \mathrm{mmHg}$. After pacemaker insertion the patient is now well.

\section{OPERATIONS}

Operative resection of the subaortic stenosis was carried out in 12 patients (Table 4). Eleven patients had a fibrous or fibromuscular diaphragm excised. The remaining patient had a subaortic ridge removed. The diaphragm was situated close to the aortic valve cusps or a short distance below them but in some cases it was situated obliquely across the left ventricular outflow tract.

The post-resection gradients measured intraoperatively showed a considerable reduction in the outflow tract gradient from that measured preoperatively in all but one patient (Table 5). In case 7 there was a slight increase in the gradient after resection of the diaphragm. The subaortic diaphragm was attached to the aortic and mitral valves and technically the resection was difficult.

Repeat operation, four years after the initial operation, was required in case 15 when a significant fibromuscular diaphragm attached to the mitral valve was noted and resected. This was followed by a repeat myotomy and wedge resection of the outflow tract.

All patients survived operation and were discharged from hospital.

\section{FOLLOW-UP}

Of the 12 patients undergoing operation one was lost to follow-up. In the remaining 11 , the postoperative follow-up ranged from one month to 11 years (mean three years). As described previously one patient had a further operation for recurrence of outflow tract obstruction four years after the first operation. All 11 patients are alive and well and are asymptomatic. Aortic regurgitation remains unchanged in 10 of the 11 patients.

In case 8 who had an aortic valve replacement with a St. Jude's valve, there was no evidence of aortic regurgitation. No patient has a mitral systolic murmur.

Heart size on chest $x$-ray film was normal in six of the eight patients who had shown an increase in the cardiothoracic ratio. In two patients heart size remained unchanged. The electrocardiogram in the 11 patients remained unchanged in five and in four there was an improvement. In two of these four who had left ventricular hypertrophy with strain pattern, the strain pattern resolved; in the other two patients 
Table 4 Operative details

\begin{tabular}{|c|c|c|c|c|c|c|}
\hline $\begin{array}{l}\text { Case } \\
\text { No. }\end{array}$ & $\begin{array}{l}\text { Cardio- } \\
\text { plegia }\end{array}$ & $\begin{array}{l}\text { Body } \\
\text { hypo- } \\
\text { thermia } \\
\left({ }^{\circ} \mathrm{C}\right)\end{array}$ & $\begin{array}{l}\text { Aortic } \\
\text { valve }\end{array}$ & $\begin{array}{l}\text { Appearance } \\
\text { of } \\
\text { diaphragm }\end{array}$ & $\begin{array}{l}\text { Direct attach- } \\
\text { ment to aortic } \\
\text { cusps and/or by } \\
\text { strand }\end{array}$ & $\begin{array}{l}\text { Direct } \\
\text { attachment } \\
\text { to mitral } \\
\text { valve }\end{array}$ \\
\hline 1 & Yes & 20 & Normal & Ring & No & Yes \\
\hline 2 & No & 30 & Abnormal & Ring & No & Yes \\
\hline 3 & Yes & 20 & Normal & Ring & No & Yes \\
\hline 4 & Yes & 25 & Normal & Ring & Yes & Yes \\
\hline 5 & Yes & 18 & Abnormal & Crescent & No & No \\
\hline 7 & Yes & 20 & Abnormal & Ring & Yes & Yes \\
\hline 8 & Yes & 20 & Abnormal & Ridge & No & Yes \\
\hline 11 & Yes & 20 & Abnormal & Ring & Yes & Yes \\
\hline 13 & No & 32 & Abnormal & Ring & No & Yes \\
\hline$\star 15$ & No & 26 & Abnormal & Ring & No & Yes \\
\hline 16 & No & 29 & Abnormal & Crescent & No & No \\
\hline
\end{tabular}

^ First operation details only

there was mild left ventricular hypertrophy by voltage criteria. In the remaining two patients assessment of left ventricular hypertrophy was not made as one had a permanent pacemaker for complete heart block and the other had left bundle-branch block.

Five patients have not as yet had operation. One of these patients has been lost to follow-up. The remaining four have been followed from four to eight years and have remained asymptomatic. In three of these four patients mild aortic regurgitation persists. There was no change in the electrocardiograms.

\section{Discussion}

Discrete subaortic stenosis often produces severe left ventricular obstruction. A peak resting systolic left

Table 5 Intra-operative pre- and post-resection outflow tract gradients

\begin{tabular}{lll}
\hline $\begin{array}{l}\text { Case } \\
\text { No. }\end{array}$ & $\begin{array}{l}\text { Pre-resection } \\
(\mathrm{mmHg})\end{array}$ & $\begin{array}{l}\text { Post-resection } \\
(\mathrm{mmHg})\end{array}$ \\
\hline 1 & 105 & 42 \\
2 & 110 & 25 \\
3 & $100^{\star}$ & 48 \\
4 & 90 & 10 \\
5 & 130 & 60 \\
& & $(25)$ Post-propranolol \\
7 & $40 \dagger$ & 54 \\
8 & 50 & 30 \\
11 & 81 & 21 \\
13 & 60 & 30 \\
15 & 110 (1st opn) & 30 \\
& $37 \dagger($ 2nd opn $)$ & 14 \\
16 & 65 & 40 \\
17 & 80 & 25 \\
\hline
\end{tabular}

* Operation three month's after catheterisation.

$\dagger$ Possibly a result of low cardiac output at the time of operation. ventricular outflow tract gradient of $50 \mathrm{mmHg}$ or more at cardiac catheterisation or operation was found in 12 of our $17(71 \%)$ patients.

Three types of discrete subaortic stenosis have been described. A subaortic membranous diaphragm which is usually thin and situated close to the aortic valve, a fibromuscular collar or ridge which is several $\mathrm{mm}$ thicker than the membranous diaphragm and lies lower in the outflow tract ${ }^{14}$, and a long segment causing a tunnel-like narrowing of the outflow tract area. Eleven of our patients had a fibrous or fibromuscular diaphragm and one had a subaortic ridge. No patient had a tunnel-like narrowing of the left ventricular outflow tract.

A high proportion of patients with discrete subaortic stenosis have symptoms in comparison with those who have congenital aortic stenosis, where in spite of severe obstruction, symptoms are rare. In 12 of $17(71 \%)$ patients, symptoms were present at the time of cardiac catheterisation or operation. Katz et $a l{ }^{2}$ found that the presence of symptoms correlated well with the degree of left ventricular outflow tract obstruction. In our series, in patients with symptoms, the peak resting systolic left ventricular outflow tract gradient ranged widely from 30 to $170 \mathrm{mmHg}$ (mean $94 \mathrm{mmHg}$ ) and in those who did not have them the gradient ranged from 26 to $70 \mathrm{mmHg}$ (mean 43). Nevertheless, the average outflow tract gradient was significantly higher for those with symptoms in comparison with those without them.

Some workers have been unable to find a correlation between symptoms, the height of the peak systolic gradient, and degree of left ventricular hypertrophy. ${ }^{5}$ In our series the electrocardiogram in all patients with symptoms showed either left ventricular hypertrophy or left ventricular hypertrophy with strain. Though there was a wide range 
in the outflow tract gradient ( 30 to $170 \mathrm{mmHg}$ ) among those with left ventricular hypertrophy, their average gradient $(86 \mathrm{mmHg})$ was higher and for those with left ventricular hypertrophy with strain, much higher (105 $\mathrm{mmHg}$ ) than for those without left ventricular hypertrophy $(29 \mathrm{mmHg})$. All patients with symptoms and left ventricular hypertrophy with strain had a high peak resting systolic left ventricular outflow tract gradient (range 50 to $170 \mathrm{mmHg}$ ).

Discrete subaortic stenosis may be a progressive disease. ${ }^{16}$ Progression may be caused by proliferation of fibrous tissue, muscular hypertrophy in the outflow tract resulting from prolonged increase in afterload or with growth of the patient the fixed narrowing may become significant. Over six years from the time of the initial presentation, nine (53\%) patients developed left ventricular hypertrophy or a strain pattern occurred in those with left ventricular hypertrophy on the electrocardiogram; in three patients a strain pattern developed within three years of the initial presentation. Two of these three patients showed a pronounced increase in obstruction in the left ventricular outflow tract as predicted by echocardiography or determined by cardiac catheterisation.

Early systolic closure of aortic leaflets together with fluttering of the aortic cusps have been characteristically recorded by $M$-mode echocardiography in patients with discrete subaortic stenosis. ${ }^{7}$ The mechanism of early systolic closure is not clearly understood. It has been suggested that because of the fixed obstruction, a jet of turbulent blood alters the normal motion of the aortic leaflets. Whether one or more leaflets are affected depends probably upon the direction of the blood flow and/or the attachment of the subaortic diaphragm to particular leaflets. Early systolic closure is not a specific sign of subaortic stenosis. ${ }^{49}$ It may occur in several conditions including mitral regurgitation, hypertrophic obstructive cardiomyopathy ${ }^{10}$, ventricular septal defect, ${ }^{15}$ or aortic dissection. ${ }^{15}$ In hypertrophic obstructive cardiomyopathy the systolic closure is usually later than that occurring with discrete subaortic stenosis. ${ }^{10}$ Early systolic closure of the aortic valve may be absent in some patients with subaortic stenosis, ${ }^{11}$ such as those who have associated intrinsic aortic valve disease. One of our patients with a bicuspid aortic valve developed bacterial endocarditis resulting in a flail aortic leaflet, and early systolic closure was not demonstrated. Though flutter of the aortic leaflets was present in all except one of our patients it is not a specific sign. It has been noted in other conditions including normal individuals, ${ }^{10}$ those with hypertrophic obstructive cardiomyopathy,${ }^{10}$ and patients with congestive cardiomyopathy (personal observation). As has been noted by other workers $^{9} 11$ no correlation was found between the early systolic closure of the aortic cusps, fine flutter of the aortic cusps and the severity of outflow tract obstruction.

Some workers using M-mode echocardiography have identified a fine, high intensity echo in the left ventricular outflow tract which is thought to represent the subaortic diaphragm. ${ }^{4816}$ As has been described ${ }^{8}$ one of our patients showed multiple echoes in the left ventricular outflow tract but no definitive diaphragm could be demonstrated. Nevertheless, using two-dimensional echocardiography, the subaortic diaphragm or ridge was identified in all seven patients studied.

The peak systolic left ventricular outflow tract gradient predicted from the echocardiogram correlated well with the gradient obtained at cardiac catheterisation or at operation. This has previously been found in patients with aortic valve stenosis. ${ }^{12} 13$ In one patient (case 1) cardiac catheterisation was not considered necessary as the predicted outflow tract gradient by echocardiogram was $127 \mathrm{mmHg}$ and no other coincidental lesions were found on twodimensional echocardiography. During the clinical surveillance of three patients (cases 5, 8, and 11) the outflow tract gradient increased as predicted by M-mode echocardiography and indicated that operation was necessary. This obviated the need for repeat cardiac catheterisation in two of these patients.

M-mode echocardiograms carried out preoperatively showed systolic anterior motion of the anterior mitral valve leaflet in three patients. One of these patients also had asymmetric septal hypertrophy (septal thickness to the left ventricular posterior wall ratio was $1.4: 1$ ). In all three patients the aortic valve closure motion suggested fixed subaortic stenosis since it occurred early after the opening of the cusps. A subaortic diaphragm was identified in all three by two-dimensional echocardiography. After resection of the subaortic fibromuscular diaphragm one of these patients showed a significant outflow tract gradient (60 $\mathrm{mmHg}$ ). After a small dose of propranolol intravenously it fell to $25 \mathrm{mmHg}$. Postoperatively in the three patients there was no evidence of the systolic anterior motion of the anterior mitral valve leaflet or asymmetric septal hypertrophy. It appears that these cases may represent a spectrum of secondary hypertrophy associated with discrete subaortic stenosis. It is possible that they may have progressed to severe and diffuse left ventricular hypertrophy if operation had not been undertaken. The association of subaortic stenosis with secondary hypertrophy and dynamic obstruction of the left ventricular outflow tract has been described. ${ }^{24} 51017$ The obstruction in subaortic stenosis is fixed in contrast with hypertrophic obstructive cardiomyopathy where the obstruction is dynamic, provoked by the position of the anterior 
leaflet of the mitral valve close to the inappropriately thickened interventricular septum in systole. At operation therefore in addition to excision of the fixed obstruction, a septal myotomy and myectomy may be necessary. It has been postulated that fixed and dynamic obstruction of the outflow tract may be interrelated particularly in the adult population. ${ }^{4}$ Among the immediate family members of our patients there was no history of fixed or dynamic obstruction of the left ventricle.

Coincidental lesions associated with discrete subaortic stenosis have been described in 10 to $62 \%$ of patients. ${ }^{135618}$ Thirty per cent of our patients had other lesions documented, for example bicuspid aortic valve and coarctation of the aorta. Occasionally the diagnosis of subaortic stenosis is missed in the presence of other associated conditions notably a large left-to-right shunt. ${ }^{1}$ If a large ventricular septal defect is proximal to the subaortic stenosis then the peak systolic outflow tract gradient is small or negligible probably as a result of decompression of the left ventricle by the left-to-right shunt. When the shunt is corrected, the left ventricular outflow tract gradient becomes evident.

A significant proportion of patients with discrete subaortic stenosis show thickened aortic leaflets. ${ }^{2} 519$ The incidence of bacterial endocarditis reported in patients with discrete subaortic stenosis varies from 13 to $25 \% .^{23}$ It may occur on the subaortic stenosis itself or on other associated coincidental lesions. Thus, the site of endocarditis may be the aortic valve, the subaortic diaphragm, and in occasional cases the outflow tract. An erosion of the obstructing diaphragm may result in loss of obstruction as a result of the endocarditis. ${ }^{2}$ In our series only one patient had bacterial endocarditis which resulted in severe aortic regurgitation.

Operation was undertaken in our patients where a peak resting systolic left ventricular outflow tract gradient $>50 \mathrm{mmHg}$ was predicted by echocardiography and/or as determined by cardiac catheterisation. In all patients except one there was a significant reduction in the outflow tract gradient immediately after operation. However, a gradient of $60 \mathrm{mmHg}$ was recorded immediately postoperatively. It is therefore imperative that these patients are closely followed. In one patient, recurrence of the outflow tract obstruction occurred four years after the initial operation necessitating a further operation. Significant left ventricular outflow tract gradients have been found postoperatively by other workers. ${ }^{1} 6141820$ These may reflect inadequate surgical resection, persistent hypertrophy of the outflow tract secondary to the prolonged fixed obstruction, or proliferation in the area of the previously resected and surviving fibrous tissue. After operation our policy is not to perform cardiac catheterisation if the patient is asymptomatic. If new symptoms develop, however, or if there is a recurrence of symptoms with the development of new changes in the electrocardiogram or persistence of a strain pattern, they are restudied. During repeat cardiac catheterisation an isoprenaline provocative test should be performed to exclude associated dynamic obstruction. ${ }^{5}$ In assessing the gradient across the outflow tract $\mathrm{M}$-mode echocardiography postoperatively is not as useful as preoperatively, as septal movement alters at operation and it may take several years to recover. Two-dimensional echocardiography can be used postoperatively, however, to assess the presence of the diaphragm and the size of the left ventricular outflow tract.

\section{References}

1 Newfeld EA, Muster AJ, Paul MH, Idriss FS, Riker WL. Discrete subvalvular aortic stenosis in childhood. Study of 51 patients. Am $\mathcal{F}$ Cardiol 1976; 38: 53-61.

2 Katz NM, Buckley MJ, Liberthson RR. Discrete membranous subaortic stenosis. Report of 31 patients, review of the literature and delineation of management Circulation 1977; 56: 1034-8.

3 Sung CS, Price EC, Cooley DA. Discrete subaortic stenosis in adults. Am $\mathcal{F}$ Cardiol 1978; 42: 283-90.

4 Ten Cate FJ, Van Dorp WG, Hugenholtz PG, Roelandt J. Fixed subaortic stenosis. Value of echocardiography for diagnosis and differentiation between various types. Br Heart f 1979; 41: 159-66.

5 Somerville J, Stone S, Ross D. Fate of patients with fixed subaortic stenosis after surgical removal. $\mathrm{Br}$ Heart $\mathrm{f}$ 1980; 43: 629-47.

6 Cassel GA, Benjamin JD, Lakier JB. Subendocardial ischaemia in patients with discrete subvalvular aortic stenosis. Br Heart $\mathcal{F}$ 1978; 40: 388-92.

7 Davis RH, Feigenbaum H, Chang S, Konecke LL, Dillon JC. Echocardiographic manifestations of discrete subaortic stenosis. Am $\mathcal{F}$ Cardiol 1974; 33: 277-80.

8 Popp RL, Silverman JF, French JW, Stinson EB, Harrison DC. Echocardiographic findings in discrete subvalvular aortic stenosis. Circulation 1974; 49: 226-31.

9 Weyman AE, Feigenbaum H, Hurwitz RA, Girod DA, Dillon JC, Chang S. Cross-sectional echocardiography in evaluating patients with discrete subaortic stenosis. Am $\mathcal{f}$ Cardiol 1976; 37: 358-65.

10 Krajcer Z, Orzan F, Pechacek LW, Garcia E, Leachman RD. Early systolic closure of the aortic valve in patients with hypertrophic subaortic stenosis and discrete subaortic stenosis. Am $\mathcal{F}$ Cardiol 1978; 41: 823-9.

11 Berry TE, Aziz KU, Paul MH. Echocardiographic assessment of discrete subaortic stenosis in childhood. Am f Cardiol 1979; 43: 957-61.

12 Glanz S, Hellenbrand WE, Berman MA, Talner NS. Echocardiographic assessment of the severity of aortic stenosis in children and adolescents. Am $\mathcal{F}$ Cardiol 1976; 38: $620-5$. 
13 Gewitz MH, Werner JC, Kleinman CS, Hellenbrand WE, Talner NS, Taunt KA. Role of echocardiography in aortic stenosis: pre- and postoperative studies. Am $\mathcal{F}$ Cardiol 1979; 43: 67-73.

14 Kelly DT, Wulfsberg E, Rowe RD. Discrete subaortic stenosis. Circulation 1972; 46: 309-22.

15 Candell-Riera J, Garcia del Castillo H, Rius J. Aortic root dissection. Another cause of early systolic closure of the aortic valve. Br Heart $\mathcal{F}$ 1980; 43: 579-81.

16 Kronzon I, Schloss M, Danilowicz D, Singh A. Fixed membranous subaortic stenosis. Chest 1975; 67: 473-4.

17 Block PC, Powell WJ Jr, Dinsmore RE, Goldblatt A. Coexistent fixed congenital and idiopathic hypertrophic subaortic stenosis. Am f Cardiol 1973; 31: 523-6.

18 Reis RL, Peterson LM, Mason DT, Simon AL, Morrow AG. Congenital fixed subvalvular aortic stenosis. An anatomical classification and correlations with operative results. Circulation 1971; 43 \& 44, suppl I: 11-8.

19 Champsaur G, Trusler GA, Mustard WT. Congenital discrete subvalvular aortic stenosis. Surgical experience and long-term follow-up in 20 paediatric patients. $\mathrm{Br}$ Heart f 1973; 35: 443-6.

20 Shariatzadeh AN, King H, Girod D, Shumacker HB Jr. Discrete subaortic stenosis. A report of 20 cases. $f$ Thorac Cardiovasc Surg 1972; 63: 258-62.

Requests for reprints to $\operatorname{Dr}$ A A J Adgey, Regional Medical Cardiology Centre, Royal Victoria Hospital, Belfast BT12 6BA, Northern Ireland. 